Research Article

\title{
Genotyping of Toxoplasma gondii in Cerebral and Ocular Toxoplasmosis
}

\author{
Dearikha Karina Mayashinta ${ }^{1}$, Ryan Halleyantoro ${ }^{2}$, Ika Puspa Sari ${ }^{3}$, Agnes Kurniawan ${ }^{3}$ * \\ ${ }^{1}$ Department of Parasitology, Faculty of Medicine, Universitas Brawijaya, Malang 65145, Indonesia \\ 2 Department of Parasitology, Faculty of Medicine, Universitas Diponegoro, Semarang 50275, Indonesia \\ ${ }^{3}$ Department of Parasitology, Faculty of Medicine, Universitas Indonesia, Depok 16424, Indonesia
}

Article history:

Submission January 2018

Revised March 2018

Accepted May 2018

*Corresponding author:

E-mail:

agnes.kurniawan@ui.ac.id

\begin{abstract}
Toxoplasma gondii is an obligate intracellular protozoon, spread world-wide and capable of infecting birds and mammals. Genetic information on T. gondii type that causes human toxoplasmosis is limited. In this study, genetic analysis of SAG2 locus was used to determine the genotype of $T$. gondii from cases with cerebral and ocular toxoplasmosis in Indonesia. Genotype determination was done directly on the clinical samples. A number of 28 cerebrospinal fluid and 8 vitreous humor positively infected with T. gondii, underwent PCR-RFLP to classify each isolate into one of three genotypes of $T$. gondii. Type I was the most common found suggesting that cerebral and ocular toxoplasmosis in Indonesia is mostly caused by type I strain of T. gondii.
\end{abstract}

Keywords: Toxoplasma gondii, genotype, PCR-RFLP, cerebrospinal fluid, ocular fluid

\section{Introduction}

Toxoplasma gondii is an obligate intracellular protozoan of phylum Apicomplexa infecting birds and mammals. It is estimated that almost one-third of global population is infected with T. gondii [1, 2]. Clinical manifestation of toxoplasmosis varies and influenced by several factors, such as duration of exposure, geographic, parasite genetics, immune status of the host, and time of infection [3]. In immunocompetent individuals, Toxoplasma infection only shows minor symptoms or even asymptomatic. On the other hand, if the infection occurs in immunodeficient individuals, clinical manifestation might be fatal or even lethal [2, 4].

Information on dynamics of toxoplasmosis cases, either continuously or periodically, is still limited and very few study reports on $T$. gondii genotype infecting human, hence $T$. gondii type is related to its pathogenic and biological character which is considered to play role in the pathogenesis and management of toxoplasmosis [5].

Toxoplasma encephalitis (TE) is one of the most common neurological infection in AIDS pa- tients. It causes significant morbidity and mortality [6]. Besides TE, T. gondii is one of the most common cause of retinochoroiditis both in immunocompetent and immunocompromised individuals [7]. Variation in biological characteristics of each $T$. gondii type is considered to cause different clinical manifestations in human.

Virulence of $T$. gondii in animals varies, depending on the type [5]. More than 95\% type of $T$. gondii isolated from North America and Europe belongs to one of three lineages, which referred to type I-III (Howe and Sibley, 1995). Genetically, the difference amongst each type is only $1-2 \%$, but virulence differs significantly [2].

Determination of three lineages by Howe and Sibley in 1995 was based on analysis of six singlecopy independent locus, one of which was surface antigen 2 (SAG 2) which is abundantly present on the parasite surface [8]. Other single gen target to determine $T$. gondii genotype is GRA 6 [9]. This study reports the type of $T$. gondii among Indonesian patients with cerebral and ocular toxoplasmosis. 


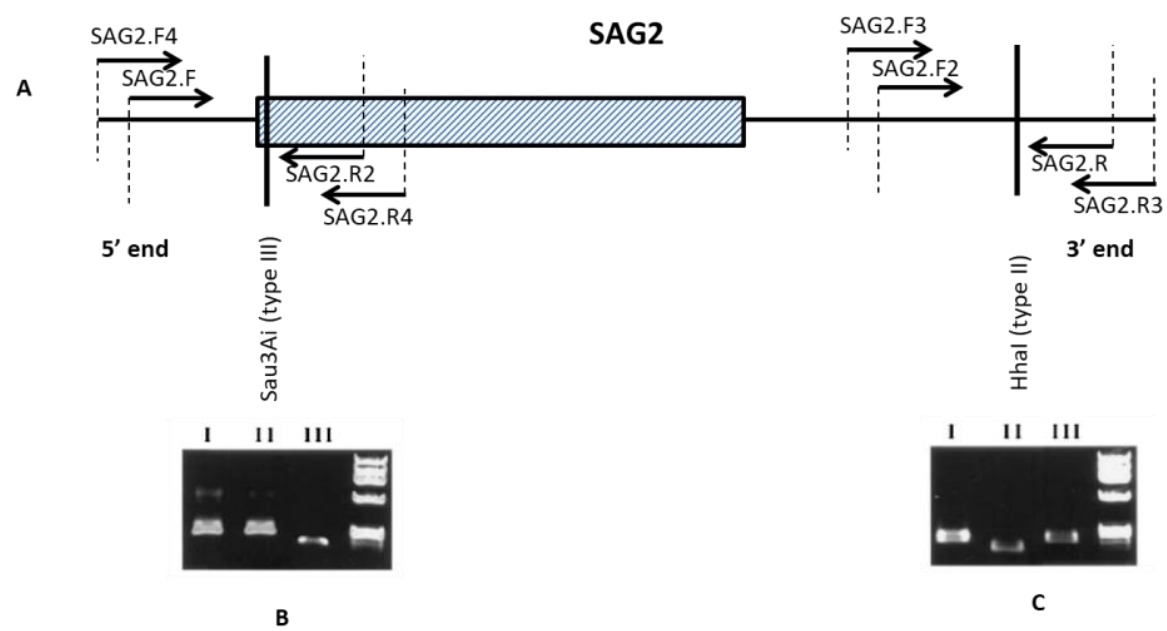

Figure 1. Genotype determination based on RFLP analysis of SAG2 gene; A) Schematic drawing of SAG2 gene; B) Sau3AI enzyme cuts allele III sequence. B) HhaI enzyme cuts allele II sequence [10].

Table 1. Primer sequences used $[4,12]$

\begin{tabular}{cllc}
\hline Target genes & \multicolumn{1}{c}{ Forward } & \multicolumn{1}{c}{ Reverse } & Amplicons \\
\hline 5'-SAG2 & nest 1(SAG2.F4): & nest 1(SAG2.R4): & \\
& GCTACCTCGAACAGGAACAC & GCATCAACAGTCTTCGTTGC & \multirow{2}{*}{ 241 bp } \\
& nest 2 (SAG2.F) & nest 2 (SAG2.R2): & \\
& GAAATGTTTCAGGTTGCTGC & GCAAGAGCGAACTTGAACAC & \\
\hline 3'-SAG2 & nest 1(SAG2.F3): & nest 1 (SAG2.R3): \\
& TCTGTTCTCCGAAGTGACTCC & TCAAAGCGTGCA TTATCGC & \multirow{2}{*}{ 221 bp } \\
& nest 2 (SAG2.F2): & nest 2 (SAG2.R): & \\
\hline & ATTCTCATGCCTCCGCTTC & AACGTTCACGAAGG CACAC & \\
\hline
\end{tabular}

\section{Material and Methods \\ Study sample}

Samples consisted of 88 cerebrospinal fluid from AIDS patients with cerebral disorder, as part of neuroaids study. While the 64 vitreous humor, obtained from patients clinically diagnosed as atypical uveitis and has been screened for Toxoplasma infection. All samples were stored in $30^{\circ} \mathrm{C}$ in Parasitology Laboratory, Faculty of Medicine, Universitas Indonesia. The study was approved by the ethical committee of Faculty of Medicine, Universitas Indonesia number 721/UN 2.F1/ETIK/2016.

\section{DNA isolation}

DNA extraction was done by boiling the samples for 10 minutes at $100^{\circ} \mathrm{C}$ [11]. For cerebral fluid, it was preceded by centrifugation of $1 \mathrm{~mL}$ of samples for 10 minutes at 10,000 rpm and leaving $150 \mu \mathrm{L}$ sediment for boiling. For vitreous humor, samples were directly boiled due to very limited volume of samples obtained $(\leq 100 \mu \mathrm{L})$.

\section{Detection of T. gondii by PCR}

To confirm T. gondii infection in cerebrospinal fluid and vitreous humor, nested PCR were performed targeting B1 gene, following the procedure by Alfonso et al. (2008) [11].

\section{Target DNA amplification for genotyping}

Strain type of $T$. gondii was determined by PCR-Restriction Fragment Length Polymorphism (RFLP) of SAG2 gene with PCR cycle condition in accordance to the protocol used by Fuentes et al. (2001), Howe et al. (1997) [4, 10]. The PCR was optimized and run in $20 \mu \mathrm{L}$ reaction using TopTaq Polymerase Master Mix Kit (Qiagen, GmbH, cat no. 200403) and $2 \mu \mathrm{L}$ DNA template on MJ Research PTC 200 thermocycler. The primers used are presented in the Table 1 . Negative control (pure water) and positive control (T. gondii RH strain, generous gift from Indonesian Research Centre for Veterinary Science) were always included in every PCR.

Optimum nested PCR condition for 5'-SAG2 
Table 2. PCR condition for 5'-SAG2 and 3'-SAG2

\begin{tabular}{clll}
\hline No & \multicolumn{1}{c}{ Condition } & \multicolumn{1}{c}{$5^{\prime}$-SAG2 } & \multicolumn{1}{c}{$3^{\prime}$-SAG2 } \\
\hline 1. & Denaturation & Nested I \& II: $94^{\circ} \mathrm{C}, 5$ minutes & Nested I \& II: $94^{\circ} \mathrm{C}, 5$ minutes \\
2. & Annealing & nested I: $60^{\circ} \mathrm{C}, 45$ seconds nested II: & nested I: $58^{\circ} \mathrm{C}, 45$ seconds; nested II: \\
& & $58^{\circ} \mathrm{C}, 45$ seconds & $55^{\circ} \mathrm{C}, 45$ seconds \\
3. & Elongation & Nested I \& II: $72^{\circ} \mathrm{C}, 1$ minutes & Nested I \& II: $72^{\circ} \mathrm{C}, 1$ minutes \\
4. & Cycle number & 40 & 40 \\
\hline
\end{tabular}
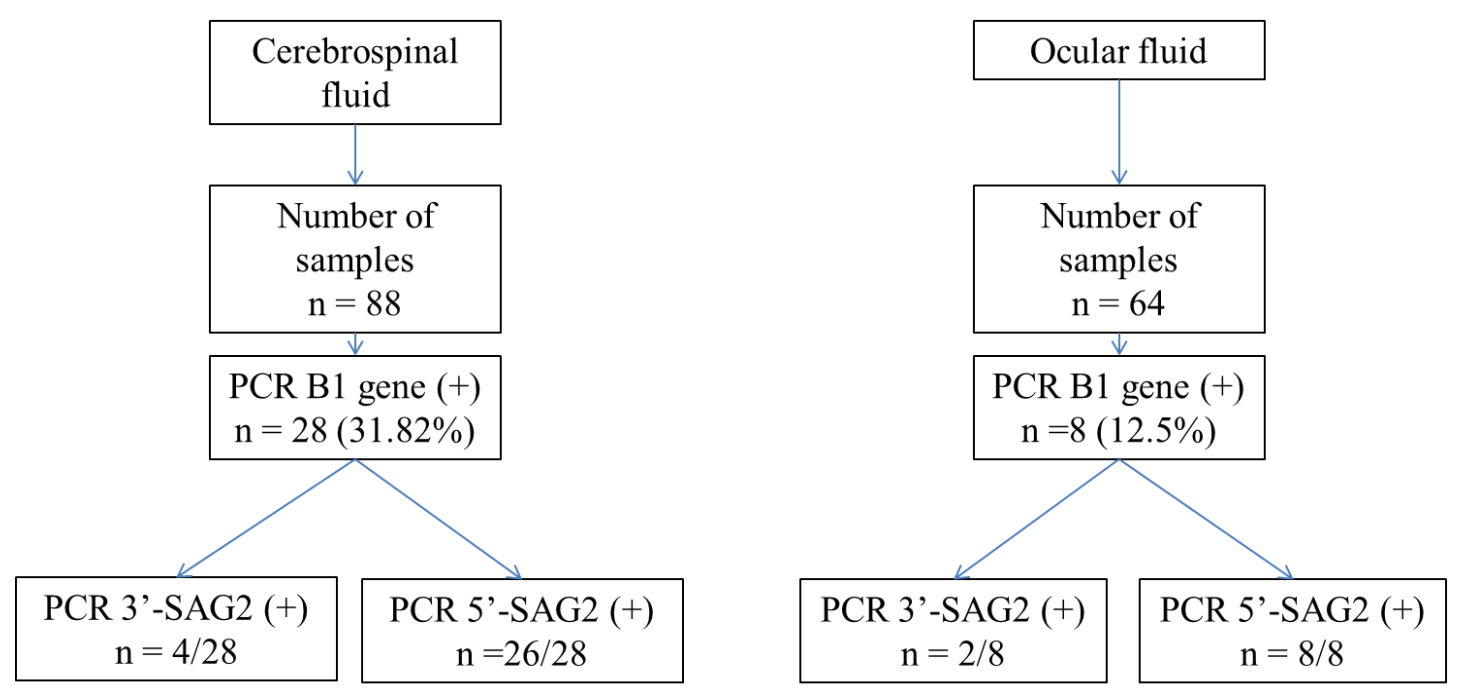

Figure 2. Work flow of T. gondii PCR of B1, 5'-SAG2 and 3'-SAG2 genes on cerebrospinal and ocular fluids

and 3'-SAG2 genes is presented in Table 2. The last cycle was extended for 10 minutes at $72^{\circ} \mathrm{C}$. The 241 bp and 221 bp of 5'-SAG2 and 3'-SAG2 respectively PCR products were visualized on $2 \%$ agarose gel electrophoresis.

The PCR products of 3'-SAG2 was digested with Hhal restriction enzymes by 4 hours incubation at $37^{\circ} \mathrm{C}$, followed by inactivation at $650 \mathrm{C}$ for 20 minutes while 5'-SAG2 PCR product was digested with Sau3AI, incubated at $37^{\circ} \mathrm{C}$ for 3 hours and inactivated at $80^{\circ} \mathrm{C}$ for 20 minutes. The reaction was performed in $15 \mu \mathrm{L}$ volume. The result was analyzed by electrophoresis on $2 \%$ agarose gel with TBE buffer solution and visualized by exposure to UV light. GeneRuler 50-bp DNA Ladder (Thermo Scientific) was used as molecular size marker. Interpretation of the result to identify the T. gondii type I/II/III.

\section{Results and Discussion}

The PCR examination of B1 gene revealed 28 out of 88 (31.82\%) cerebrospinal fluid samples and 8 out of 64 (12.5\%) ocular fluid were positive for T. gondii infection. PCR of the 28 spinal fluid previously B1 gene positive, showed fewer positive result which were 26/28 and 4/28 samples res- pectively on 5'-SAG2 and 3'-SAG2. Similar result was obtained for the 8 ocular fluid samples, which were $100 \%$ positive on the 5'-SAG2 PCR however only 2/8 samples were positive on 3'-SAG2 gene.

\section{RFLP of gene SAG2 PCR products}

The size of amplicon for 5'-end was 241 bp and for 3'-end was 221 bp. PCR products were then digested by endonuclease restriction enzyme, HhaI to digest 3'-end and Sau3AI to digest 5'-end. Genotype analysis results by RFLP shown in Table 3.

Until recently, there is no report of human $T$. gondii genotypes in Indonesia and whether certain genotype is related to certain clinical manifestation is still a debate. Several methods can be used to investigate $T$. gondii types, from isoenzyme electrophoresis, restriction fragment length polymorphism (RFLP), multiplex PCR, DNA microsatellite analysis, and DNA sequencing [5, 13, 14, 15]. Of all above, PCR-RFLP is the most common method used in more than 1,000 isolates in the world and had produced significant data on $T$. gondii genetic variation [16].

This work is part of a study on neuroaids where Toxoplasma laboratory screening has been 
Table 3. Genotyping of T. gondii from spinal and ocular fluid

\begin{tabular}{lcccc}
\hline Samples & $\begin{array}{c}\text { Type I } \\
(\%)\end{array}$ & $\begin{array}{c}\text { Type I or } \\
\text { II (\%) }\end{array}$ & $\begin{array}{c}\text { Type } \\
\text { III } \\
(\%)\end{array}$ & $\begin{array}{c}\text { Total } \\
(\%)\end{array}$ \\
\hline CSF & 4 & 22 & 0 & 26 \\
& $(15.38 \%)$ & $(84.62 \%)$ & $(0 \%)$ & $(100 \%)$ \\
Ocular & 2 & 6 & 0 & 8 \\
fluid & $(25 \%)$ & $(75 \%)$ & $(0 \%)$ & $(100 \%)$ \\
\hline
\end{tabular}

performed by PCR on B1 gene, resulted in 28/88 (31.82\%) cerebrospinal fluid samples and 8/64 (12.5\%) of aqueous humor were positive for $T$. gondii. The incidence of active cerebral toxoplasmosis in our study is higher than ocular toxoplasmosis, as well as to similar study on HIV infected patients in Malaysia, which was 11.3\% [17].

Studies about prevalence of ocular toxoplasmosis in Asia showed various results. In India, the incidence varied from $1.7-12 \%$, while in Japan, T. gondii is only responsible for $1.1 \%$ of uveitis cases; $8.7 \%$ of uveitis cases in Thailand were caused by T. gondii [18]. Mahalakshmi et al. (2010) also reported that B1 gene is generally more sensitive to detect $T$. gondii DNA compared to SAG2, though SAG2 is able to rapidly distinguish $T$. gondii genotype as it has polymorphic sites specific for each type [19].

Studies on genetic analysis of $T$. gondii, reported that amplification of SAG2 required only small amount of DNA sample, which make it possible to be applied directly on clinical samples [4]; thus, important information about various $T$. gondii strain from patients suspected from clinical toxoplasmosis can be analyzed [10]. The Surface Antigen Gene 2 (SAG2) codes T. gondii P22 protein, the main surface protein showing good antigenicity and immunogenicity characteristic. It is suitable for rapid genotyping because it has specific polymorphism for each type of T. gondii [19].

Our study showed that amplification of 5'SAG2 gene of $T$. gondii was very good, resulted in $92.8 \%$ of 28 cerebrospinal fluid and $100 \%$ of 8 aqueous / vitreous humor were positive. The good result on 5'-SAG2 gene was not replicable for PCR of 3'-SAG2, which gave positive result in only $14.3 \%$ of 28 spinal fluids and $25 \%$ of 8 samples aqueous/vitreous humor previously positive on B1 screening. The failure to amplify locus SAG2 might be caused by the small amount of parasite in the samples [10]. The presence of polymorphism in primer attachment site of the studied isolates is also possible [20].

Amplicons of SAG2 gene, both 5' and 3'ends were then subjected to RFLP to reveal the genotype based on digestion by Sau3AI and HhaI restriction enzymes. Sau3AI recognize restriction site on $T$. gondii type III, whereas HhaI enzyme can recognize restriction site on $T$. gondii type II. Samples which are not digested by both enzymes suggested the type I [10].

Genotyping by PCR-RFLP on cerebrospinal fluid samples could only be accomplished in 4 samples which were successfully amplified the 5'and 3' SAG2 genes, resulted as type I $T$. gondii (figure 3). The rest 22 spinal fluids which were PCR positive merely on 5'-SAG2, the RFLP could distinguish between type III and non-type III (I/II), resulted all to be non type III. No type III was found in the spinal fluid samples.

As genotyping of $T$. gondii from aqueous/vitreous humor could only be performed on 2 samples which completely amplified both SAG2 genes, resulted in type I. The rest 6 samples which only amplified 5'-SAG2 were found to be either type I or II strain. None of the aqueous/vitreous humor samples was of type III strain.

Various studies reported that type I was the most pathogenic strain in immunocompromised patients. A study in Brazil showed $46 \%$ patients were found to be infected by type I strain [6]. Similar results were also reported by Khan et al. (2005), among 11 samples obtained from HIV infected patients and diagnosed as Toxoplasma encephalitis, were infected by type I T. gondii [15].

Identification of $T$. gondii type in aqueous/vitreous humor in this study showed similar result as with the spinal fluids i.e. Type I or type II strains of $T$. gondii. This result is supported by prior study result in Brazil which found only type I strain in all 11 ocular samples positive for T. gondii [21]. There were also three other reports documenting isolation of $T$. gondii from immunocompetent adults with ocular toxoplasmosis. Two of the isolation, which were performed in mice were virulent towards mice, so it is likely type I, or at least not type II Nor type III, suggesting that type I strain is the most related to ocular toxoplasmosis in immunocompetent adults [7].

Nevertheless, the data above are contradictive 


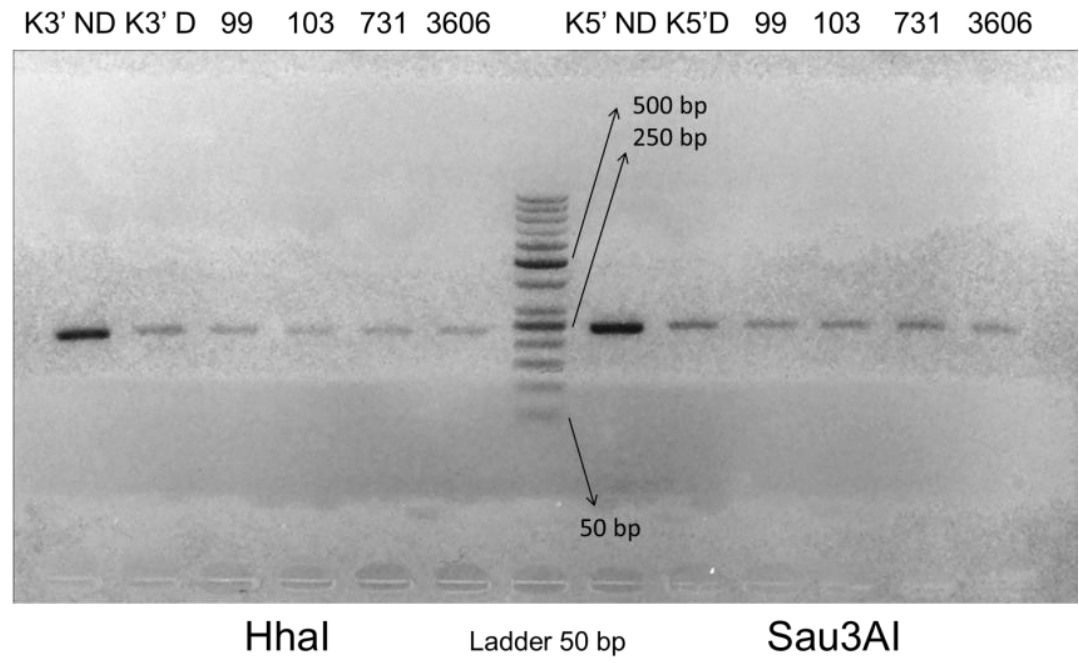

Figure 3. HhaI and Sau3AI RFLP showing none of the PCR products were digested.

with the notion that type II is the most related to toxoplasmosis [22]. It is likely to be caused by limitation in sample analysis which used only one gene target to determine the parasite genotype, and it is strongly suggested that the strain which causes lesion in brain or eye is a mixed infection or because the genetic difference amongst strain is indeed very little [21]. Genetically, the difference amongst each type is only $1-2 \%$, but the virulence differs significantly [2]. SAG2 gene is useful in distinguishing type I, II, and III, but in this study, we did not find atypical strain as it is commonly found in Southern America [6]. Besides, characterization of genotype with gene SAG2 can be performed directly in clinical samples, thus it prevents bias in prevalence of certain type contributed by duplications of certain type in culture process [20].

Other aspect to be noted in direct genotyping is the failure in amplification of some samples using standard protocol as described by Howe et al (1997) [10]. It could be due to the presence of polymorphism in primer attachment sites among the Indonesian isolates, which are different geographically compared to other countries isolates [20].

\section{Conclusion}

Type I and likely type II are the most common strain found in T. gondii infection of brain and eye. This study is the first research on genotyping of $T$. gondii in Indonesia. A genotyping method with higher resolution is needed to understand the effect of various genetic background amongst $T$. gondii strain with clinical manifestation and transmission pattern in Indonesia.

\section{Acknowledgment}

Authors would say thanks to:

1. Master Program in Biomedical Sciences, Faculty of Medicine, Universitas Indonesia.

2. Parasitology Department, Faculty of Medicine, Universitas Indonesia.

3. Post-graduate scholarship program from Ministry of Research, Technology and Higher Education.

\section{References}

1. Robert-Gangneux F, Darde ML (2012) Epidemiology of and diagnostic strategies for toxoplasmosis. Clinical Microbiology Reviews 25 (2): 264 - 296. doi: 10.1128/CMR.05013-11.

2. Weilhammer DR, Rasley A (2011) Genetic approaches for understanding virulence in Toxoplasma gondii. Briefings in Functional Genomics 10 (6): 365 - 373. doi: 10.1093/bfgp/elr028.

3. Fekkar A, Ajzenberg D, Bodaghi B et al. (2011) Direct genotyping of toxoplasma gondii in ocular fluid samples from 20 patients with ocular toxoplasmosis: Predominance of type II in France. Journal of Clinical Microbiology 49 (4): 1513 - 1517. doi: 10.1128/JCM.02196-10.

4. Fuentes I, Rubio JM, Ramirez C, Alvar J (2001) Genotypic characterization of Toxoplasma gondii strains associated with human toxoplasmosis in Spain: Direct analysis from clinical samples. Journal of Clinical Microbiology 39 (4): 1566 - 1570. doi: 10.1128/JCM.39.4.1566-1570.2001.

5. Subekti DT, Arrasyid NK (2006) Imunopatogenesis Toxoplasma gondii berdasarkan perbedaan galur. Wartazoa 16: 128 -145 . 
6. Ferreira IMR, Vidal JE, Costa-Silva TA et al. (2008) Toxoplasma gondii: Genotyping of strains from Brazilian AIDS patients with cerebral toxoplasmosis by multilocus PCR-RFLP markers. Experimental Parasitology 118 (2): 221 - 227. doi: 10.1016/j.exppara.2007.08.006.

7. Grigg ME, Ganatra J, Boothroyd JC, Margolis TP (2001) Unusual abundance of atypical strains associated with human ocular toxoplasmosis. The Journal of Infectious Diseases 184 (5): 633 - 639. doi: 10.1086/322800.

8. Howe DK, Sibley LD (1995) Toxoplasma gondii comprises of parasite three clonal lineages: Correlation with human disease genotype. The Journal of Infectious Diseases 172 (6): 1561 1566. doi: 10.1093/infdis/172.6.1561.

9. Fazaeli A, Carter PE, Darde ML, Pennington TH (2000) Molecular typing of Toxoplasma gondii strains by GRA6 gene sequence analysis. International Journal for Parasitology 30 (5): 637 - 642. doi: 10.1016/S0020-7519(00)00036-9.

10. Howe DK, Honore S, Derouin F, Sibley LD (1997) Determination of genotypes of Toxoplasma gondii strains isolated from patients with toxoplasmosis. Journal of Clinical Microbiology 35 (6): 1411 - 1414.

11. Alfonso Y, Fraga J, Cox R et al. (2008) Comparison of four DNA extraction methods from cerebrospinal fluid for the detection of Toxoplasma gondii by polymerase chain reaction in AIDS patients. Medical Science Monitor 14 (3): 1-7.

12. Zakimi S, Kyan H, Oshiro M et al. (2015) Genetic characterization of GRA6 genes from Toxoplasma gondii from pigs in. Journal of Veterinary Medical Science 68 (10): 1105 - 1107. doi 10.1292/jvms.68.1105.

13. Su C, Zhang X, Dubey JP (2006) Genotyping of Toxoplasma gondii by multilocus PCR-RFLP markers: A high resolution and simple method for identification of parasites. International Journal of Parasitology 36 (7): 841 - 848. doi: 10.1016/j.ijpara. 2006.03.003.

14. Ajzenberg D, Cogne N, Paris L et al. (2002) Genotype of 86 Toxoplasma gondii isolates associated with human congenital toxoplasmosis, and correlation with clinical findings. The Jour- nal of Infectious Diseases 186 (5): 684 - 689. doi: $10.1086 / 342663$.

15. Khan A, Su C, German M et al. (2005) Genotyping of Toxoplasma gondii strains from immunocompromised patients reveals high prevalence of type I strains. Journal of Clinical Microbiology 43 (12): 5881 - 5887. doi: 10.1128/JCM.43.12.588 1-5887.2005.

16. Shwab EK, Zhu XQ, Majumdar D et al. (2014) Geographical patterns of Toxoplasma gondii genetic diversity revealed by multilocus PCR-RFLP genotyping. Parasitology 141: 453 461. doi: 10.1017/S0031182013001844.

17. Nissapatorn V, Lee C, Quek KF et al. (2004) Toxoplasmosis in HIV/AIDS patients: A current situation. Japanese Journal of Infectious Diseases 57:160 - 165 .

18. Furtado JM, Winthrop KL, Butler NJ, Smith JR (2013) Ocular toxoplasmosis I: Parasitology, epidemiology and public health. Clinical and Experimental Ophthalmology 41 (1): 82 - 94. doi: 10.1111/j.1442-9071.2012.02821.x.

19. Mahalakshmi B, Therese KL, Kirthika R et al. (2010) Evaluation of nested PCRs targeting the BI and SAG2 genes for detection of Toxoplasma gondii genome in aqueous humor from HIV positive toxoplasma retinochoroiditis patients in a tertiary eye hospital. Current Research in Medicine 1 (2): 157 - 163. doi: 10.3844/amjsp.2010.157.163.

20. Gallego C, Saavedra-Matiz C, Gomez-Martin JE (2006) Direct genotyping of animal and human isolates of Toxoplasma gondii from Colombia (South America). Acta Tropica 97 (2): 161 167. doi: 10.1016/j.actatropica.2005.10.001.

21. Vallochi AL, Muccioli C, Martins MC et al. (2005) The genotype of Toxoplasma gondii strains causing ocular toxoplasmosis in humans in Brazil. American Journal of Ophthalmology 139 (2): 350 - 351. doi: 10.1016/j.ajo.2004.07.040.

22. Boothroyd JC, Grigg ME (2002) Population biology of Toxoplasma gondii and its relevance to human infection: Do different strains cause different disease?. Current Opinion in Microbiology 5 (4): 438 - 442. doi: 10.1016/S1369-5274(02)003491. 